\title{
Instructional Innovations with Business Communication in Classrooms: Practice-Based Presentation Topics and Online Communication Tools
}

\author{
Young Sun Lee \\ University of Rochester, New York, NY, USA
}

Objectives: Communication skills are critical for productive performance in a professional workplace, and many employers look for the skills in their new hires. This paper shares an innovative approach to business communication education which combines practice-based presentation topics with online communication practice tools.

Method: Included in this paper are four individual presentation rounds with suggested topics and steps for each round. Two newly launched communication recording/practice tools - PitchVantage and GoReact - are described. These online communication practice tools not only ease instructors/facilitators' physical efforts and save them time, but also enable students to practice and prepare for their presentations more efficiently.

Results: Through the lesson and practice, in-class student presentation grades were shown to be improved. Student's self-assessments also reflected the teaching methods and templates/matrixes helped them improve their skillsets.

Conclusion: Students want to become a competitive candidate or employee in their target company or industry. Employers look for a candidate who can be a good fit for their company. Business communication courses should focus on practical communication skills development that will enable students to be competitive job candidates/employees.

Key Words: Business Communication, Presentation, Curriculum, Communication Practice, Communication Technology

\section{Introduction}

Recent reports and surveys consistently conclude that communication is one of the most important skills for career success (Graduate Management Admission Council, 2017; Robles,

Received: Jul 13, 2019 Revised: Sept 1,2019 Accepted: Sept 12, 2019 Corresponding author: Young Sun Lee University of Rochester, 300 Wilson Blvd, Rochester, NY 14620, USA Tel: +1-585-276-6672, E-mail: youngsun.lee@simon.rochester.edu

This is an Open Access article distributed under the terms of the Creative Commons Attribution Non-Commercial License (http://creativecommons.org/licenses/ by-nc/4.0/) which permits unrestricted non-commercial use, distribution, and reproduction in any medium, provided the original work is properly cited.

Copyright ( 12020 Korean Association for Business Communication.
2012). According to the GMAC (Graduate Management Admission Council) 2017 Corporate Recruiters Survey Report, communication skills rank highest among the skills employers consider most important, followed by teamwork, technical skills, leadership skills, and managerial skills. Employers are likely to choose job candidates with soft skills over those with hard/technical skills (Robles, 2012; Russell, Russell, \& Tastle, 2005) and many business leaders expect higher learning institutions to develop the communication skills of their students and provide them with internship and practical experience opportunities before they graduate (Gallup-Lumina Foundation, 2014). As a result of understanding the importance of communication skills for the success of their students in the long term, many 
business schools include development of these skills in their curriculum (Du-Babcock, 2006; Russ, 2009).

It is clear that communication skills (oral, written, listening, and interpersonal) are critical for productive performance in a professional environment, and many employers look for communication skills in their new hires. Yet many employers and recruiters report that many recent business school graduates come to the workplace lacking communication skills (Nealy, 2005; Ortiz, Region-Sebest, \& MacDermott, 2016), even though they have adequate hard skills (Driscoll, 2011; Mitchell, Skinner, \& White, 2010).

Many researchers have addressed possible reasons for why business students lack communication skills. Although many business schools admit the importance of communication skills, they still require traditional business courses (such as finance, marketing, or accountancy) mandatory and designate communication courses as electives (Chang, Park, \& Cho, 2018). Also, the concept of communication in the business world is broad and complex with different levels, such as individual, group, and organizational communication (Lunenburg \& Ornstein, 2008). Since communication can be general that can draw from many disciplines, business communication can be interpreted as including business writing, business English, marketing communication, intercultural communication, and negotiation (Chang et al., 2018).

Given the importance of communication skills to business school graduates, this paper suggests to business communication instructors presentation topics and procedures students can be directed in to further develop their communication skills.

\section{Case Description}

\section{Background}

The business school where the author currently works has a one-year master's program in four different areas (finance, accounting, marketing analytics, and business analytics). Each academic year, approximately three hundred ninety students take a required business communication course and the students must pass the course in order to graduate. Classes run from the middle of July to mid-December, and there are four individual presentation assignments (one every four weeks) during the semester. Included in this paper are the materials used with the business analytics students.

Before students start their first semester, they are asked to complete a survey about their previous professional communication experiences and to evaluate their communication skills from several aspects (oral, writing, etc.) at school or work. Students usually indicate that they are afraid of speaking in front of people or using "English" in front of people since many of the students are from outside of the U.S. As to their professional communication/public speaking confidence level, the class average for 2019 was about 6 out of 10 .

Presentation topics in the business analytics communication course vary from job interviews to project visualizations. Before the first individual presentation round, students are introduced to Aristotle's Theory of Rhetoric and its three appeals - logos (logic), ethos (credibility), and pathos (emotions). Students watch selected TedTalk videos and try to identify examples of the appeals being used the talks. They learn that knowing the audience well is one the most important elements for successful persuasive messages. For several of the classes leading up to each presentation, students are assigned informal speeches such as a one-minute self-introduction talk and a one-minute "change the world" presentation to get them more comfortable speaking in front of others.

\section{Step-by-Step Procedures}

\section{Round 1 Presentation: Why Hire Me?}

For this presentation students learn to convey to employers their unique skills, strengths, and abilities in 4-5 minutes. They learn how to assess their audience, organize messages for maximum impact (hiring), and communicate messages convincingly. The students are told that the audience for this presentation includes a company recruitment coordinator, a department head, and an alumnus of the business school (Excerpt 1).

Normally, students know what they are good at or what they have accomplished. However, when they are in a situation where they need to pitch within a set time, or need to deliver messages in front of the job-recruiting people, they find such presenting challenging. Instructors provide the students with a matrix, and students develop their contents step by step. Detailed instructions can be available from the corresponding author upon request.

\section{Excerpt 1. Presentation scenario in Round 1}

You recently met a university alumnus at a networking event. The alumnus was impressed with you and has invited you to meet some members of his company. The alumnus has arranged for you to speak with an HR coordinator, a department head and themselves. They've asked you to prepare a short 4-5-minute presentation about yourself, highlighting your key skills. This is not an interview, so you will not be asked questions. You are simply presenting yourself as a student about to enter the industry. You will need to the company but remember, this is a presentation about you, not about the company. 
Round 2 Presentation: Industry Analysis "Viewpoint on an Industry's Key Issue"

The goal of this presentation is to expand students' ability to speak as a knowledgeable and thought-provoking professional in the industry they have chosen for their career (Excerpt 2). The key requirement for this presentation is to develop a point of view. Students should go beyond delivering a report on the industry and instead take a position in regard to it - a perspective on the industry that they can convince their audience is based on solid data and sound reasoning. The audience for this presentation includes a company HR coordinator, a department head, and a business school alumnus.

Usually, students are encouraged to have three main points for their presentations, and they are told that 'three' is the ideal number. An audience typically can't remember the main theme of the presentation if there are more than three points in the presentation. And having fewer than three main points in a presentation makes the presentation seem too simple.

\section{Round 3 Presentation: What's the Implication?}

The purpose of this assignment is to expand students' ability to speak as a knowledgeable professional on an issue or trend in the business arena using the concepts, theories, and ideas discussed in other courses. The key requirement for this presentation is to defend students point of view using concepts from their economics class as well as persuasion techniques learned in their business communication course. Detailed instructions can be available from the corresponding author upon request.

\section{Round 4 Presentation: Choose Your Own Topic}

The presentation is designed to help students practice skills in analyzing research and expand their ability to present the results of work. For this presentation, they enhance ability to design and use graphic aids in a presentation using Tableau (see examples in Figure 1). The dataset they use for this presentation is Kaggle.com. Kaggle is the world's largest community of data scientists and machine learners, owned by Google. Students follow several steps to develop the presentation (instructions available on request).

Excerpt 2. Presentation scenario in Round 2

Your previous presentation (Round 1: "About Me") impressed your audience, and the same HR coordinator, department head, and business school alumnus have now asked you to give a 5-minute presentation about a key issue their company's industry faces right now. Specifically, they want you to answer the following question: Why is a key issue the industry faces right now?

Communication Tools for Practice: How Technologies Can Help Students' Communication Skills?

During the presentation rounds, students get to use several online tools. PitchVantage is an AI (Artificial Intelligence) generated online tool that students can use while practicing for their presentations, and GoReact is an online tool that instructors use in the classroom to record students' presentations live.

\section{Pitch Vantage}

Professional communicators build confidence in themselves by polishing their public speaking skills (Stettner, 2018). Pitch-

A

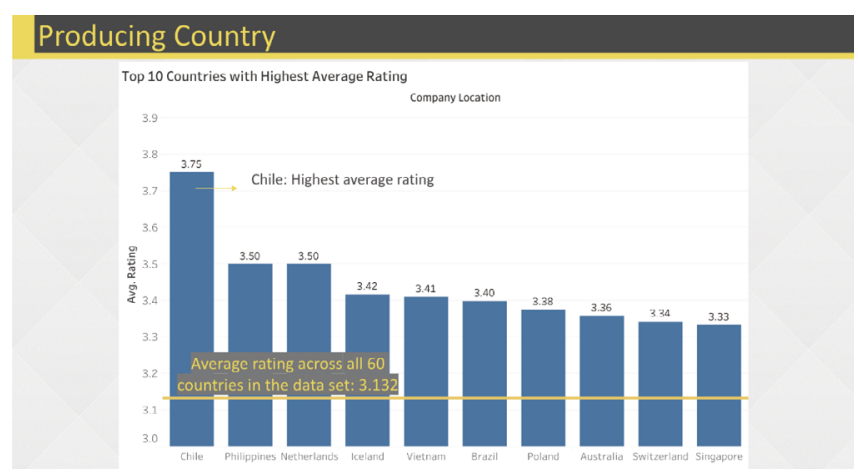

B

Most common words in titles

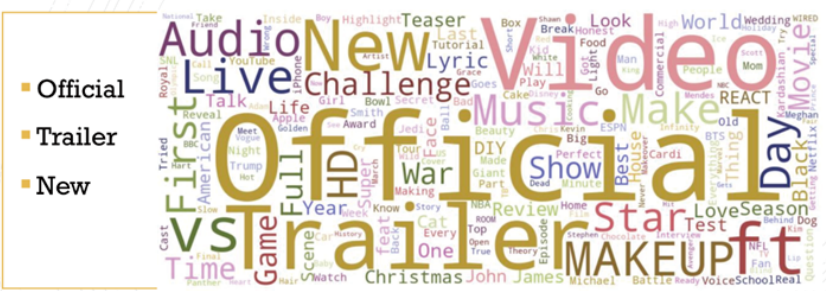

C

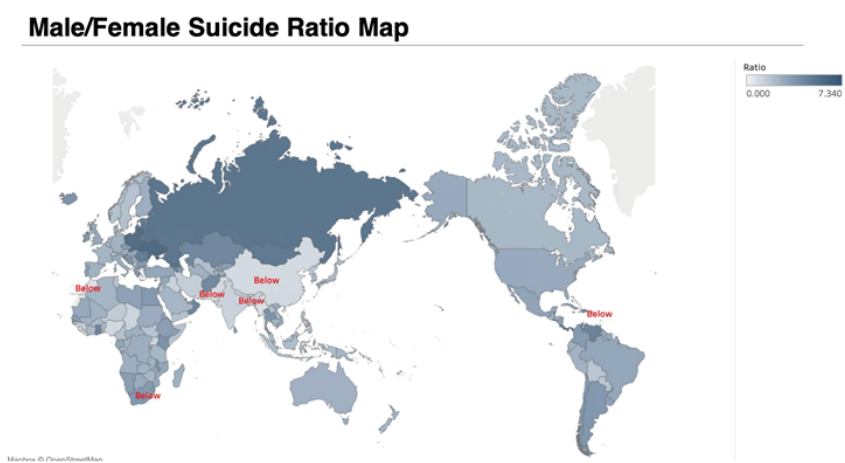

Figure 1. Student presentation visualization examples using Tableau. (A) Top 10 Countries with highest average rating, (B) Most common words in titles, (C) Male/female suicide ratio map. 
Vantage is a tool that provides real-time feedback to presenters to help them stay on track, to master nonverbal cues, and to avoid stammering. Students can practice their presentation in front of simulated virtual audiences. The audience reacts as the speaker presents. When he or she speaks too fast and does not having proper pauses, the AI audience will become distracted and look elsewhere, not at the speaker. If a presenter speaks without vocal variation, the audience will show indifference and stop engaging with the presentation. When a speaker performs well (with a good level of vocal variation, pauses, etc.), the AI audience will look at the speaker and the heads of the audience will nod.

According to PitchVantage's website (http://www.pitchvantage.com), students receive instant feedback on ten aspects of presentation delivery with personalized tips that help them improve: pitch variability, pace variability, volume variability, verbal distractors, pauses, pace, long pauses, engagement, volume and eye contact (Figure 2).

During the semester, students are asked to practice using PitchVantage at least five times (for a minimum of five minutes for each practice session) before they present in class. Those who complete the practice sessions with this tool earn an extra point for their presentation. Students have the option of releas-

\section{A}

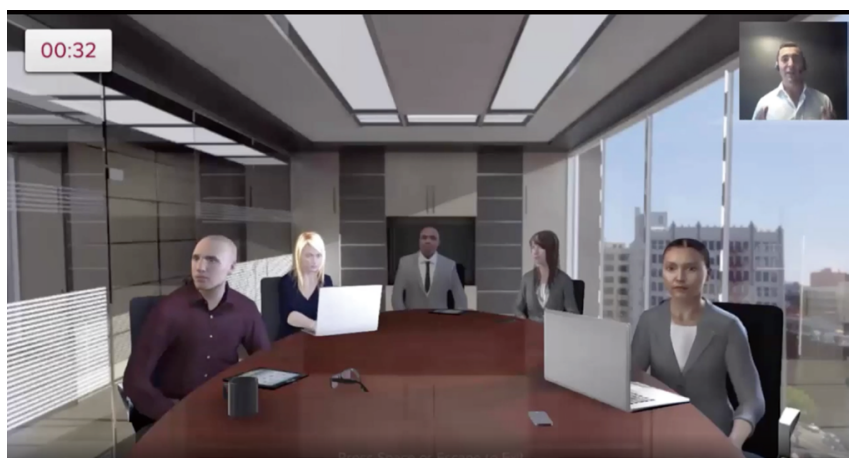

B

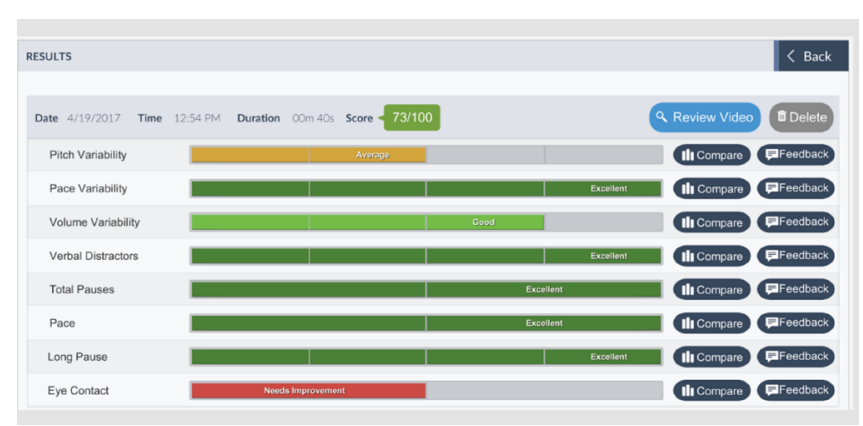

Figure 2. PitchVantage example: (A) Al audience simulation, (B) instant feedback based on ten aspects. $\mathrm{Al}$, artificial intelligence. ing their practice recordings to their instructor. Instructors can see all individual scores and recommend areas for improvement (such as pause variability, volume variation).

\section{GoReact}

When educators use recordings to "show" rather than "tell" students how they can improve their speaking skills, students benefit more from their practice sessions and reflect more deeply on their performance because they are visual learners (McMahon, 2019). GoReact is a tool that allows educators to capture live presentations and give instant feedback. It does not require any additional equipment to record; with a smartphone or webcam, instructors can capture students' presentations in classrooms. Videos are securely stored in the cloud, so if an instructor cannot physically attend a presentation, any facilitator can record the presentations and instructors or graders can review them later from the cloud.

Business communication instructors can use this tool to record student presentations and give feedback after each session. Previously, presentations were recorded by the IT team of the business school; the IT team had to set up a camera, save the recording in a server, and cut the recording into individual presentations, send the presentations back to instructors. With GoReact, it is easy for the instructors to record and give feedback on the presentations in a timely manner. And students learn faster because they can see time-stamped feedback at exactly the right moment. GoReact enables instructors to make time-coded comments during the presentation so that students can understand where they made mistakes or what to improve for next time (Figure 3).

\section{Review Sessions}

\section{On-the-Spot Peer Feedback}

For each round, instructors assign non-presenting students to be feedback providers and ask them to critique specific aspects of the presentation such as structure/content, speaking skill, visual presence, and the effectiveness of PowerPoint slides. Students watch their peers' presentations and make specific comments that they learn what elements are important for effective presentations.

\section{Self-Reflection after Performance}

Previously, feedback on students' presentations were likely to be somewhat general because the feedback provider could not tell where the mistakes were made or could not give specific comments at the right moment. Moreover, now students can watch their own presentations from online tools like GoReact or PitchVantage and write a self-reflection on two-three strengths 

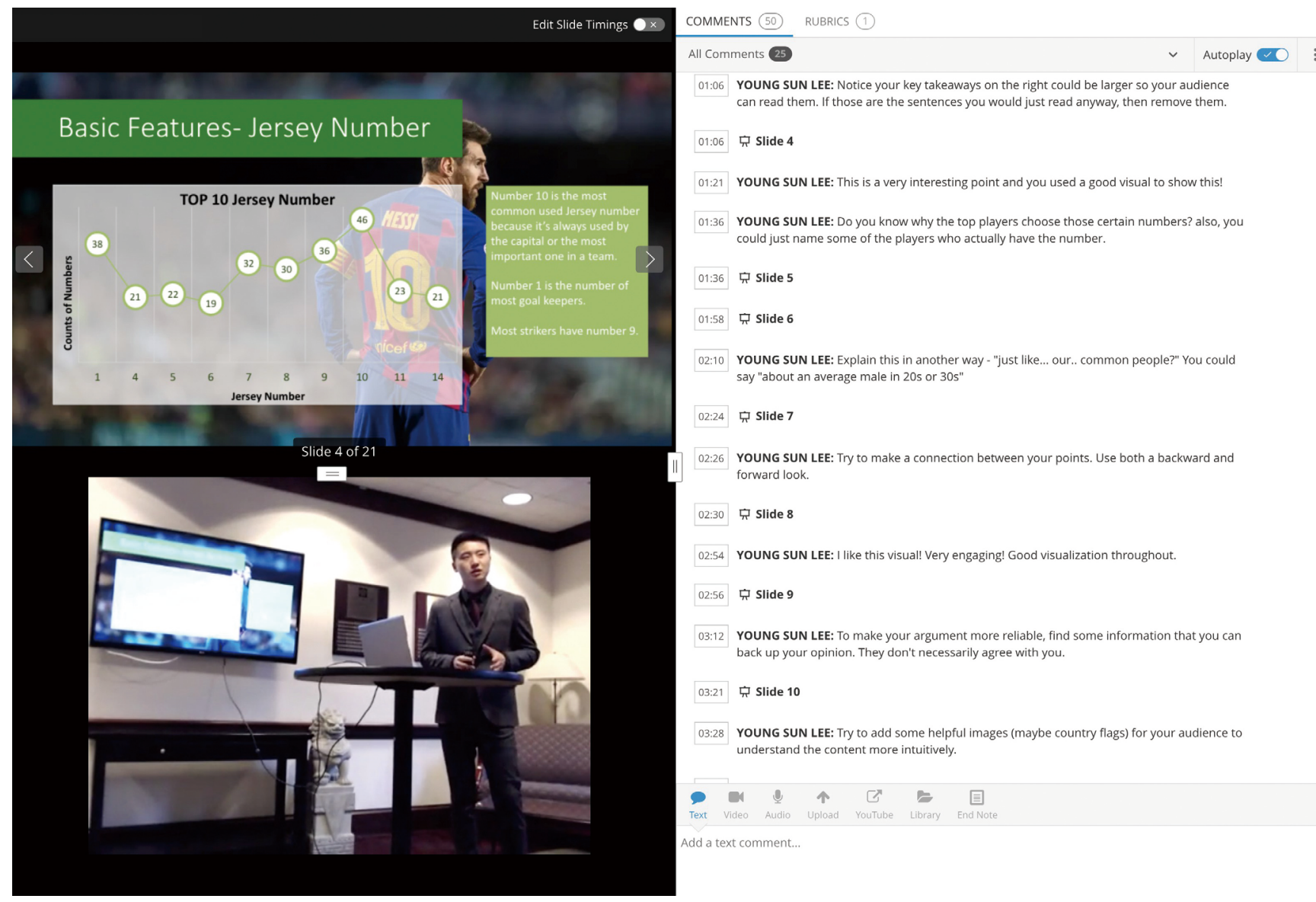

Figure 3. Student presentation and time-stamped feedback using GoReact.

of their presentation: 1) What did you do well that you will want to repeat in your next presentation? 2) Was there anything in your presentation which allowed you to be successful? Also, the students need to address areas for improvement for their next presentation: 1) Identify what went wrong and why it happened and discuss your actionable ideas for improvement. 2) What will you do to address these issues? How will you change your presentation?

Once students complete their final individual presentation, I ask them to review their last presentation on GoReact and compare it with their previous presentations. Specifically, 1) Assess your progress throughout the semester. 2) Choose three areas where you have improved as a speaker and discuss what strategies you learned to improve each area. 3) Reflect on your process towards becoming a better speaker.

I gather all of students' submissions and make a word cloud to show what words have been mentioned most frequently in their self-reflection (see example in Figure 4). Students come to realize how important the audience is for their presentation, and they come to understand other elements (such as eye contact, body/hand gestures, time management, practice) as also important.

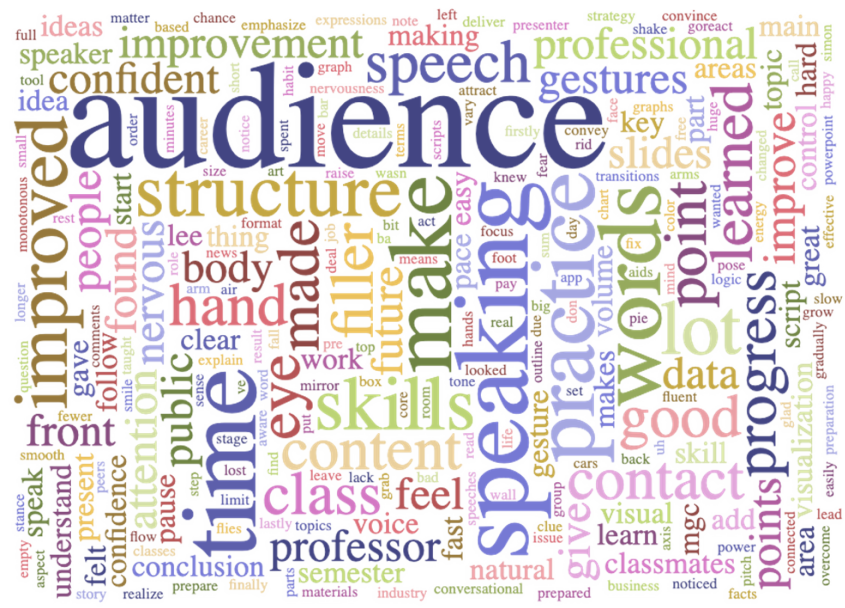

Figure 4. Word cloud example based on student's self-reflection.

\section{Evaluation}

The students' grades show they performed gradually better. The average scores for the 126 students' individual presentations were: 25.6 (85\%) in Round 1, 25.4 (85\%) in Round 2, 26.1 (87\%) 
in Round 3, and 26.9 (90\%) in Round 4. Some of the students' self-reflections from the last presentation round also confirmed that the teaching methods and technologies used were helpful to them for developing their skills, as shown in Excerpt 3.

\section{Discussion}

Soft skills, including effective communication, teamwork, work ethic, and professionalism are critical in today's workplace and should be considered as an investment (Robles, 2012). Companies continue to rate their employees' communication skills as more important than their technical competence (Klaus, 2010). Therefore, business school educators should also be clear that development of communication skills is as important as technical competence for students who want to find and keep jobs (Evenson, 1999; Robles, 2012). Moreover, educators should realize the need for a curriculum that meets both students' and industry's demands (Chang et al., 2018).

The purpose of this article is to share an innovative approach to business communication education using practice-based presentation topics and online communication practice tools. Based on the students' improved presentation performance during the semester and their written self-reflection assignments above, feedback during the learning process was one of the most important elements for their growth and development.

\section{Importance of Self-Reflection}

I found that students realized their weaknesses during the self-re- flection assignments and then planned more precisely for the next round of presentations. Assigning repeated self-reflections could be something that other business communication course instructors would want to consider emulating in their communication courses. Much educational research identifies self-reflection as a key element for self-regulation and is considered critical for future motivation and performance (De Grez, Valcke, \& Roozen, 2009; Schunk, Meece, \& Pintrich, 2012). Because self-reflection involves time-allocation, evaluation of performance, as well as discovery of improvements strategies and helpful learning aids (Masui \& De Corte, 2005), the self-reflection process moves students forward in their skills development (Zimmerman, 1998).

\section{Learning from Others through Peer Feedback}

Not only does self-reflection help students improve their performance, so also does on-the-spot peer feedback. Through peer feedback, individuals grow in confidence, also known as self-efficacy, individual's belief in one's capacity to execute the performance in a given situation (Bandura, 1977). One of the four sources of self-efficacy is "vicarious experience", and it refers to observing "similar others" succeeding (Bandura, 1977). Because students take their communication courses by program (all business analytics students are grouped together for their classes), students quickly perceive their peers as "similar others". Each student observes directly at least ten other peers' presentations in each session and the presentation session repeats itself four times, so they have ample opportunity to see others present. Moreover, GoReact saves all other students' presentations and makes them available

Excerpt 3. Students' self-reflections from the last presentation

Student A: "I used to worry a lot about giving a presentation. Now I no longer feel very nervous. This is the biggest improvement. ..... I have developed the habit of following a good structure. As long as I can think of good materials, I will always try my best to follow the complete structure (introduction with an opening, three parts in the body, and a conclusion with a closing). I have practiced this structure in each of my presentations and using an outline/matrix has become a habit for me."

Student B: "The most progress I made through four rounds of presentations relates to my structure. I began to familiarize myself with how to structure my speech to let my audience know my points clearly. It's because I am able to adapt the matrix and outline that the professor provided. With the help of the matrix and outline, I could think about the topic thoroughly before I wrote the script. I will stick to using the matrix and outline in my future presentations so that I can be as clear as possible even with longer presentations."

Student C: "I became more natural and confident talking in front of people. Before this class, I haven't learned systemically how to communicate and how to give presentations even though I always enjoy talking in front of people. In the last round of presentations, I used Pitch Vantage for rehearsing and I found it very helpful. It has a timer and a reaction-based audience in front of me, so it forced me to keep going and to adjust my presentation."

Student D: "I learned a lot about how visualization helps me get through my points. I often used slides in my presentation, but I rarely paid attention to the potential problems I made or the points I should focus on, such as consistency. Those intense practices in class and presentations helped me a lot to be a better presenter with effective visualizations." 
to those who take the same course, thereby enabling students to see all other classmates' presentations whenever they want to. Many students have mentioned that they are very grateful for the support they receive from their classmates, and have indicated that they learned a lot by watching their peers present. Thus, the peer feedback can generate a strong sense of support and camaraderie among students and instill in each student a desire to grow.

\section{Conclusion}

This paper includes examples of presentation topics for communication skill development. It also introduces new tools that educators can use for recording in-class presentations live and students can use to practice presentations skills using AI (artificial intelligence) simulation for instant feedback. Integrating communication skills into the business school curriculum will help students overcome their weaknesses and prepare them for the workplace. This case report can be a source for practice-oriented activities for a business communication course. When students learn about key communication aspects to consider and then practice knowing what to include in their presentations, their potential anxiety diminishes and their confidence grows. Anyone interested in teaching business communication or learning how to give effective presentations can learn useful information here.

\section{References}

Bandura, A. (1977). Self-efficacy: Toward a unifying theory of behavioral change. Psychological Review, 84(2), 191-215.

Chang, H., Park, P., \& Cho, S. (2018). An analysis of business communication courses in business schools and suggestions for curriculum development. Business Communication Research and Practice, 1(1), 33-40.

De Grez, L., Valcke, M., \& Roozen, I. (2009). The impact of goal orientation, self-reflection and personal characteristics on the acquisition of oral presentation skills. European Journal of Psychology of Education, 24(3), 293-306.

Driscoll, E. (2011, March 4). Um, like, whatever: College grads lack verbal skills. Fox Business. Retrieved from https://www.foxbusiness. com/features/um-like-whatever-college-grads-lack-verbal-skills

Du-Babcock, B. (2006). Teaching business communication: Past, present, and future. The Journal of Business Communication, 43(3), 253-264.

Evenson, R. (1999). Soft skills, hard sell. Techniques: Making Education \& Career Connections, 74(3), 29-31.

Gallup-Lumina Foundation (2014). The 2013 LUMINA study of the American public's opinion on higher education and U.S. business leaders poll on higher education: What America needs to know about higher education redesign. Retrieved from https:// www.luminafoundation.org/files/resources/2013-gallup-luminafoundation-report.pdf

Graduate Management Admission Council. (2017). Market Intelligence Corporate Recruiters Survey Report 2017. Retrieved from https://www.gmac.com/-/media/files/gmac/research/ employment-outlook/2017-gmac-corporate-recruiters-webrelease.pdf

Klaus, P. (2010). Communication breakdown. California Job Journal, 28(1248), 1-9.

Lunenburg, F. C., \& Ornstein, A. O. (2008). Educational administration: Concepts and practices. Thousand Oaks, CA: Wadsworth.

Masui, C., \& De Corte, E. (2005). Learning to reflect and to attribute constructively as basic components of self-regulated learning. British Journal of Educational Psychology, 75(3), 351-372.

McMahon, W. (2019, May 14). This professor uses video to show not tell - student teachers how to hone their craft. Retrieved from https://www.edsurge.com/news/2019-05-14-this-professor-usesvideo-to-show-not-tell-student-teachers-how-to-hone-their-craft

Mitchell, G. W., Skinner, L. B., \& White, B. J. (2010). Essential soft skills for success in the twenty-first century workforce as perceived by business educators. Delta Pi Epsilon Journal, 52(1), 43-53.

Nealy, C. (2005). Integrating soft skills through active learning in the management classroom. Journal of College Teaching \& Learning, 2(4), 1-6.

Ortiz, L. A., Region-Sebest, M., \& MacDermott, C. (2016). Employer perceptions of oral communication competencies most valued in new hires as a factor in company success. Business and Professional Communication Quarterly, 79(3), 317-330.

Robles, M. M. (2012). Executive perceptions of the Top $10 \mathrm{soft}$ skills needed in today's workplace. Business and Professional Communication Quarterly, 75(4), 453-465.

Russ, T. L. (2009). The status of the business communication course at US colleges and universities. Business Communication Quarterly, 72(4), 395-413.

Russell, J., Russell, B., \& Tastle, W. J. (2005). Teaching soft skills in a systems development capstone class. Information Systems Education Journal, 3(19), 3-19.

Schunk, D. H., Meece, J. R., \& Pintrich, P. R. (2012). Motivation in education: Theory, research, and applications. Boston, MA: Pearson.

Stettner, M. (2018, November 11). Build confidence and boost your creativity. Investor's Business Daily. Retrieved from https:// www.investors.com/news/management/leaders-and-success/ build-confidence-promote-innovation/

Zimmerman, B. J. (1998). Developing self-fulfilling cycles of academic regulation: An analysis of exemplary instructional models. In D. Schunk \& B. J. Zimmerman (Eds.), Self-regulated learning: From teaching to self-reflective practice (pp. 1-19). New York, NY: Guildford Press. 